\title{
Editorial
}

\section{Using Remote Sensing Techniques to Improve Hydrological Predictions in a Rapidly Changing World}

\author{
Yongqiang Zhang ${ }^{1, * \mathbb{D}}$, Dongryeol Ryu ${ }^{2} \mathbb{D}$ and Donghai Zheng ${ }^{3} \mathbb{(}$ \\ 1 Key Laboratory of Water Cycle and Related Land Surface Processes, Institute of Geographic Sciences and \\ Natural Resources Research, Chinese Academy of Sciences, Beijing 100101, China \\ 2 Department of Infrastructure Engineering, Faculty of Engineering and Information Technology, \\ The University of Melbourne, Melbourne, VIC 3010, Australia; dryu@unimelb.edu.au \\ 3 National Tibetan Plateau Data Center, State Key Laboratory of Tibetan Plateau Earth System, Resource and \\ Environment, Institute of Tibetan Plateau Research, Chinese Academy of Sciences, Beijing 100101, China; \\ zhengd@itpcas.ac.cn \\ * Correspondence: yongqiang.zhang2014@gmail.com or zhangyq@igsnrr.ac.cn; Tel.: +86-10-64856515
}

check for updates

Citation: Zhang, Y.; Ryu, D.; Zheng, D. Using Remote Sensing Techniques to Improve Hydrological Predictions in a Rapidly Changing World. Remote Sens. 2021, 13, 3865. https://doi.org/ $10.3390 /$ rs13193865

Received: 22 September 2021 Accepted: 26 September 2021 Published: 27 September 2021

Publisher's Note: MDPI stays neutral with regard to jurisdictional claims in published maps and institutional affiliations.

Copyright: (c) 2021 by the authors. Licensee MDPI, Basel, Switzerland. This article is an open access article distributed under the terms and conditions of the Creative Commons Attribution (CC BY) license (https:// creativecommons.org/licenses/by/ $4.0 /)$.

\begin{abstract}
Remotely sensed geophysical datasets are being produced at increasingly fast rates to monitor various aspects of the Earth system in a rapidly changing world. The efficient and innovative use of these datasets to understand hydrological processes in various climatic and vegetation regimes under anthropogenic impacts has become an important challenge, but with a wide range of research opportunities. The ten contributions in this Special Issue have addressed the following four research topics: (1) Evapotranspiration estimation; (2) rainfall monitoring and prediction; (3) flood simulations and predictions; and (4) monitoring of ecohydrological processes using remote sensing techniques. Moreover, the authors have provided broader discussions, on how to make the most out of the stateof-the-art remote sensing techniques to improve hydrological model simulations and predictions, to enhance their skills in reproducing processes for the fast-changing world.
\end{abstract}

Keywords: remote sensing; model; hydrological prediction; climate change; land use change; evapotranspiration

\section{Introduction}

We are living in a world where geophysical datasets, particularly, remote sensing datasets, are created at fast increasing rates [1]. The efficient and innovative use of these datasets for understanding hydrological processes in various climatic and vegetation regimes under anthropogenic influence has become an important challenge, which offers a wide range of research opportunities at the same time [2,3]. This is particularly urgent for the hydrological research community at large who has relied on both spatially distributed and lumped hydrological models for hydrological simulations/predictions over the last several decades [4]. The demand for increasingly accurate water information spatially distributed at high resolution requires a deeper understanding of the underlying processes and more skillful predictions, at resolutions that do not commensurate with the traditional hydrological data. This is an important challenge to the conventional hydrological modelling.

To address these challenges, efforts need to be made to innovatively integrate various remote sensing techniques into hydrological simulations and predictions, which is more critical in a changing world. This Special Issue of Remote Sensing contributes towards this aim through investigations on how a better and smarter use of high-to-moderate-resolution remote sensing datasets can improve hydrological simulations and predictions. Ten peerreviewed papers are published in this Issue, which are grouped into four categories using remote sensing techniques: 
- Evapotranspiration estimation;

- Rainfall monitoring and prediction;

- Flood simulations and predictions; and

- Monitoring ecohydrological processes.

\section{Contributed Papers}

\subsection{Estimating Evapotranspiration}

In this category, two papers are published. Zhang and Song et al. [5] estimated the Evapotranspiration (ET) of Beijing city at a 10-m resolution, using vegetation information from Sentinel-2 satellite data. For the first time, monthly ET at a $10 \times 10-\mathrm{m}$ resolution for the Beijing Sponge City was estimated, using a water-carbon coupling model (PML-V2) driven by the 10-m resolution of the Sentinel-2-based Leaf Area Index (LAI), Sentinel-2-based land cover classification data, and surface meteorological data. Model validations show that the Sentinel-2-based LAI has a good correlation $\left(R^{2}=0.74\right)$ with the observed values. The PML-V2-estimated ET compares well $\left(R^{2}=0.64-0.90\right)$ with the flux measurements at three fields within the Beijing region. Model simulation results show that LAI, ET, and the Gross Primary Productivity (GPP) are $0.83 \mathrm{~m}^{2} \mathrm{~m}^{-2}, 1.6 \mathrm{~mm} \mathrm{~d}^{-1}$, and $2.8 \mathrm{gC} \mathrm{m}^{-2} \mathrm{~d}^{-1}$, respectively, during June 2018. Water bodies, including lakes and rivers, show the highest ET of $>8 \mathrm{~mm} \mathrm{~d}^{-1}$, followed by mixed forest and croplands that have ET varying in $4-6 \mathrm{~mm} \mathrm{~d}^{-1}$ and grasslands with ET varying in $2-4 \mathrm{~mm} \mathrm{~d}^{-1}$. Compared to these land cover types, the impervious surface occupying $\sim 60 \%$ of the sponge city areas shows the smallest ET of $<2.0 \mathrm{~mm} \mathrm{~d}^{-1}$. This study demonstrates that it is feasible to use the highresolution satellite data to have detailed simulations of hydrological processes in urban ecosystems. Jepsen et al. [6] analyzed the suitability of remotely sensed ET for calibrating a hydrological model in the upper Kings River watershed $\left(3999 \mathrm{~km}^{2}\right)$ of California's Sierra Nevada, a snow-influenced watershed in a Mediterranean climate. They compared a spatiotemporal pattern of ET from a remote-sensing product, MODIS MOD16A2, to that from a hydrological model (SWAT) calibrated against an observed streamflow. The ET estimates from both MOD16A2 and SWAT modelling were evaluated against observations from three flux towers at elevations of 1160-2700 m. It was found that the SWAT-modelled ET performs better than MOD16A2 ET, indicated by the Nash-Sutcliffe efficiency $(+0.36$ versus -0.43$)$ and error in the elevational trend $(+7.7 \%$ versus $+81 \%)$. For this particular modelling experiment, the authors concluded that it is challenging for the remotely sensed ET product used for watershed-model parameter estimation. By analyzing ET-weather relationships, the authors found that the relatively large errors in MODIS ET may be related to weather-based corrections to water limitation not representative of the hydrology of this snow-influenced, Mediterranean-climate area. Therefore, attention should be paid when using global ET products (such as MOD16A2) at a watershed scale, particularly when the watershed involves snowmelt processes. Moreover, it is necessary to have bias corrections of the ET data before use for model parameterization [7].

\subsection{Rainfall Monitoring and Prediction}

In this category, two papers are published. Han et al. [8] investigated the potential to use next-generation millimeter-wave backhaul technologies for rainfall monitoring in a dense urban environment. Traditionally, microwave backhaul links are mainly used for communications between cellular base stations. In this study, the authors used the links for measuring the path-averaged rain rate. In particular, they investigated the rain attenuation characteristics in Gothenburgh, Sweden using the new microwave backhaul techniques at different mmWave frequencies and link lengths. They found that estimating the pathaverage rainfall using mmWave links is very effective. The mmWave link measurementderived rain rate is very well correlated $(R=0.8-0.9)$ to the local measurement from rainfall gauges. Their study indicates that there is a great potential to use the mmWave links for monitoring rainfall in urban areas. Liu et al. [9] investigated how the assimilation frequency of radar reflectivity affects the rain storm prediction in the Daqinghe basin 
of northern China, using the Three-Dimensional Variational Data Assimilation (3DVAR) system of the Weather Research Forecast (WRF) model. Their results show that the WRF3DVAR system noticeably improves its performance for predicting the location, tendency, and development of rain storm, using the assimilation of radar reflectivity and Global Telecommunication System (GTS) data collectively. Moreover, this study suggests that it is important to validate and correct the assimilated measurement data before performing data assimilation, which can benefit not only prediction accuracy but also assimilation efficiency.

\subsection{Flood Simulations and Predictions}

In this category, four papers are published. Ma et al. [10] conducted a flash flood warnings study in Yunnan Province, China using NASA's Integrated Multi-Satellite Retrievals for Global Precipitation Measurement (GPM-IMERG) precipitation products. They tested two GPM-IMERG products: The near-real-time IMERG Early run product (IMERG-E) and the post-real-time IMERG Final run product (IMERG-F) with a 6-h temporal resolution. The results show that MERG-F is better than IMERG-E over the study area, indicated by an hourly R of 0.46 and relative bias of $23 \%$. Furthermore, the IMERG-F results are well corresponding to the gauge data when using the Rainfall Triggering Index (RTI) model for calibration, suggesting that MERG-F is suitable for flash flood warnings. Wang et al. [11] investigated if the prediction of flash flood can be improved for mountainous catchments of northern China using the WRF-3DVAR module through coupled atmospheric-hydrologic systems. Compared to the baseline (openloop) model run, the assimilation improved the accuracy of rainfall accumulation as well as provided more accurate flood forecasting. Based on the grid-based Hebei model, an atmospheric-hydrological coupling system was established and performed by predicting the flash flood as well as obtaining the best performance of Nash-Sutcliffe Efficiency (NSE) $=0.874$ after assimilation, compared to NSE $=0.64$ before assimilation. Moreover, the authors pointed out the need to carefully transfer hydrological parameters, since the locally derived hydrodynamic parameters may not be applicable to mesoscale areas. Zhu et al. [12] proposed a modelling framework for the urban flood analysis in ungauged catchments using short-term and high-resolution rainfall data. The framework includes three steps. First, generate extreme rainfall events using a rainfall generator named RainyDay together with a 9-year record of hourly, $0.1^{\circ}$ remotely sensed rainfall data. Second, simulate runoff using an Urban Hydrological Model (SWMM) under different rainfall return periods and durations. Third, analyze urban flood using flood indicators, such as flood time, maximum rainfall rates, and total maximum rainfall volume. This framework was tested in Guagzhou city, China. The results show that a combination of RainyDay and short-term remotely sensed rainfall data can expand the rainfall records for urban hydrological simulations and predictions. Furthermore, the proposed framework shows a good performance for runoff process simulation, especially for high return periods or long durations (NSE > 0.90), demonstrating that the proposed framework has potential for urban flood analysis in ungauged catchments. Yasir et al. [13] analyzed and simulated runoff processes in a heavily regulated river basin, the Lhasa River where there are Zhikong and Pangduo hydropower dams changing hydrological regimes. The analysis indicates that the Lhasa River streamflow shows stronger variations during 2000-2016, compared to pre-2000. The Zhikong hydropower plant and the Pangduo power plant began operations in 2006 and 2013, respectively, which strongly influence the Lhasa River streamflow. The modelling results indicate that the SWAT hydrological model is capable of simulating the streamflow under reservoir influence, and can be used for predicting future streamflow. The predicted streamflow has a similar behavior to the observation while decreasing in the years from 2017 to 2025, indicating that the hydrological regimes in this region are simultaneously affected by climate change and anthropogenic impacts. Yang et al. [14] proposed a new method using an Unmanned Aerial Vehicle (UAV) combined with the incipient motion of stone to calculate the peak streamflow of ephemeral rivers in northwestern China. Critical initial velocities of moving stones were estimated using two methods: Logarithmic and exponential velocity distribution methods. Their 
results indicate that the exponential velocity distribution method outperforms the logarithmic method. Under high flood events $\left(>20 \mathrm{~m}^{3} / \mathrm{s}\right)$, the proposed method can achieve model errors less than $10 \%$. Under a low streamflow condition $\left(1 \mathrm{~m}^{3} / \mathrm{s}\right)$, the accuracies are relatively low. Nevertheless, this study provides an alternative way to calculate streamflow in ungagged rivers, which are particularly useful for peak flood estimation. The proposed approach is easy to apply and has potential for large-scale application, considering the quick advance of the UAV technology.

\subsection{Monitoring Ecohydrological Processes}

In this category, one paper is published. Qiao et al. [15] investigated how water transfer in arid northwestern China influences the wetland ecosystem via surface and groundwater interactions. In arid and semiarid regions, water transfer is a useful way to prevent vegetation degradations and maintain healthy ecosystems. This study analyzed the spatiotemporal pattern of vegetation coverage before and after water transfer in Qingtu Lake and the surrounding area. The results show that water transfer from the upstream contributes to the expansion of water bodies and vegetation, particularly for the condition of fractional vegetation coverage of $30-50 \%$. The groundwater and soil water content increase can remain at high levels for the following months after water transfer, suggesting that the transferred water can be stored as ground water or soil water due to the strong surface and subsurface interactions, which provide water use for vegetation in the following year.

\section{Editorial Summary and Comments}

There are various ways that remote sensing techniques are used to improve hydrological simulations and predictions, enhancing our collective efforts. The efforts can be summarized into, but not limited to, the following categories: (1) Detecting hydrological and other related changes using state-of-the-art remote sensing techniques; (2) mapping eco-hydrological and hydrological processes and their driving factors using large samples and high-resolution datasets; (3) understanding hydrological processes in a rapidly changing world using hydrological modelling together with high-to-moderate-resolution (several meters to hundred meters) remote sensing data; (4) improving hydrological prediction skills by modifying hydrological model structures to incorporate remote sensing data and using various model calibrations against remote sensing data; (5) developing hydrological modelling frameworks using advanced cloud cluster computation techniques and tools, such as the Google Earth Engine; (6) using remote sensing data together with data assimilation or/and machine learning techniques to improve predictions of various hydrological variables and hydrological signatures; and (7) using remote sensing techniques for waterrelated studies, such as on the water-food-energy security nexus. Although the ten papers published in this Special Issue only cover parts of the summarized categories, we believe that continued efforts in using remote sensing techniques in hydrology definitely promote the development of hydrology, particularly in the fields of fusion of hydrological model and remote sensing and ground observations that cover all of the categories 1-7 (Figure 1).

In fact, the first guest editor and his team (we) had put lots of efforts in these categories and shared some researches below. For instance, we used the Google Earth Engine platform to develop a carbon-water coupled model (PML-V2) for estimating the actual evapotranspiration and gross primary production products across the global land surface with $500 \mathrm{~m}$ and 8-day resolution for the period of 2002 to 2020 [16]. This is a particular example followed in the categories of 2,3, and 5. Another example of category 4 is to develop state-of-the-art model-data fusion techniques for predicting runoff in ungauged catchments. We used remotely sensed ET data only to calibrate hydrological model parameters. Since it does not require observed streamflow data for model calibration, it has the great potential runoff prediction in poorly gauged or ungauged regions. We demonstrate that this approach is very useful in Australia [17] and China [7] after bias corrections. Last but not least, we modify the rainfall-runoff modelling structure for better incorporating remote sensing data. The reasoning is that traditional rainfall-runoff models do not have a structure to simulate 
the impact of Land Use and Land Cover Change (LUCC), and are not reliable to simulate hydrological processes with rapid LUCC. We modified traditional rainfall-runoff models by changing their submodule for describing soil moisture and actual evapotranspiration processes $[18,19]$. The modified rainfall-runoff models improve hydrological simulations noticeably in the catchments experiencing rapid land cover changes [18].

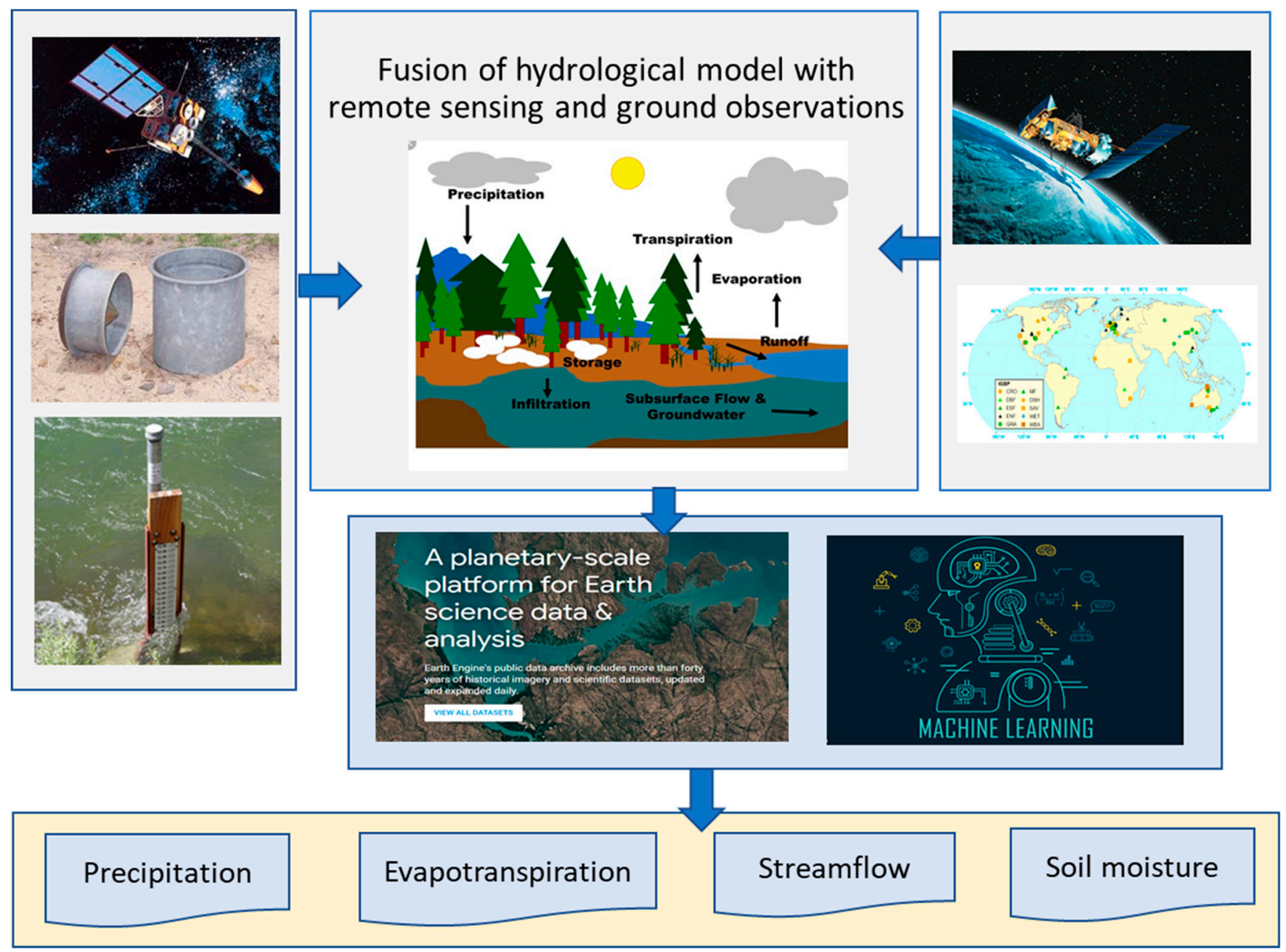

Figure 1. Conceptualized summary of model and data fusion techniques for improving hydrological predictions.

\section{Conclusions}

The world is quickly changing with land surface conditions changing dramatically due to anthropogenic impacts over the last two decades. Correspondingly, geophysical datasets, particularly, remote sensing datasets, are created at fast increasing rates. It is challenging to efficiently and innovatively use these datasets for understanding hydrological processes in various climatic and vegetation regimes under anthropogenic impacts, which also offer a wide range of research opportunities. To address these challenges, efforts need to be undertaken to use various remote sensing techniques to improve hydrological simulations and predictions in a changing world. Ten peer-reviewed papers were published in this Special Issue, and can be summarized into the following four categories:

- Estimating evapotranspiration;

- Rainfall monitoring and prediction;

- Flood simulations and predictions; and

- Monitoring ecohydrological processes. 
The ten papers presented in this Special Issue reflect the efforts for improving hydrological simulations and predictions using various remote sensing techniques. The papers published in this issue advance the remote sensing of hydrology by applying a new measurement approach, such as UAV or model-data fusions. Though the published ten papers in this Special Issue only cover parts of the summarized categories, we believe that continuous efforts in using remote sensing techniques in hydrology definitely promote hydrology. Furthermore, the authors more broadly discuss how to smartly use the state-of-the-art remote sensing techniques to improve hydrological model simulations and predictions to tackle a quickly changing world.

Author Contributions: Y.Z. conceived and led the development of the Special Issue and this paper; D.R. and D.Z. each contributed to the writing of this paper. All authors have read and agreed to the published version of the manuscript.

Funding: This study is supported by the CAS Pioneer Talent Program and the National Natural Science Foundation of China (grant no. 41971032).

Institutional Review Board Statement: Not applicable.

Informed Consent Statement: Not applicable.

Data Availability Statement: Not applicable.

Acknowledgments: As guest editors of this Special Issue, we thank the journal editors and all the authors submitting manuscripts to this Special Issue. Our thanks are extended to the referees who put great efforts in reviewing the submissions, which is the cornerstone for the high-quality publications of Remote Sensing.

Conflicts of Interest: The authors declare no conflict of interest.

\section{References}

1. Pekel, J.-F.; Cottam, A.; Gorelick, N.; Belward, A.S. High-resolution mapping of global surface water and its long-term changes. Nature 2016, 540, 418-422. [CrossRef] [PubMed]

2. $\quad$ Rodell, M.; Famiglietti, J.S.; Wiese, D.N.; Reager, J.T.; Beaudoing, H.K.; Landerer, F.W.; Lo, M.H. Emerging trends in global freshwater availability. Nature 2018, 557, 650-659. [CrossRef] [PubMed]

3. Pulliainen, J.; Luojus, K.; Derksen, C.; Mudryk, L.; Lemmetyinen, J.; Salminen, M.; Ikonen, J.; Takala, M.; Cohen, J.; Smolander, T.; et al. Patterns and trends of Northern Hemisphere snow mass from 1980 to 2018. Nature 2020, 581, 294-298. [CrossRef] [PubMed]

4. Pascolini-Campbell, M.; Reager, J.T.; Chandanpurkar, H.A.; Rodell, M. A 10 per cent increase in global land evapotranspiration from 2003 to 2019. Nature 2021, 593, 543-547. [CrossRef] [PubMed]

5. Zhang, X.; Song, P. Estimating Urban Evapotranspiration at 10m Resolution Using Vegetation Information from Sentinel-2: A Case Study for the Beijing Sponge City. Remote Sens. 2021, 13, 2048. [CrossRef]

6. Jepsen, S.M.; Harmon, T.C.; Guan, B. Analyzing the Suitability of Remotely Sensed ET for Calibrating a Watershed Model of a Mediterranean Montane Forest. Remote Sens. 2021, 13, 1258. [CrossRef]

7. Huang, Q.; Qin, G.; Zhang, Y.; Tang, Q.; Liu, C.; Xia, J.; Chiew, F.H.S.; Post, D. Using Remote Sensing Data-Based Hydrological Model Calibrations for Predicting Runoff in Ungauged or Poorly Gauged Catchments. Water Resour. Res. 2020, 56, e2020WR028205. [CrossRef]

8. Han, C.; Huo, J.; Gao, Q.; Su, G.; Wang, H. Rainfall Monitoring Based on Next-Generation Millimeter-Wave Backhaul Technologies in a Dense Urban Environment. Remote Sens. 2020, 12, 1045. [CrossRef]

9. Liu, Y.; Liu, J.; Li, C.; Yu, F.; Wang, W. Effect of the Assimilation Frequency of Radar Reflectivity on Rain Storm Prediction by Using WRF-3DVAR. Remote Sens. 2021, 13, 2103. [CrossRef]

10. Ma, M.; Wang, H.; Jia, P.; Tang, G.; Wang, D.; Ma, Z.; Yan, H. Application of the GPM-IMERG Products in Flash Flood Warning: A Case Study in Yunnan, China. Remote Sens. 2020, 12, 1954. [CrossRef]

11. Wang, W.; Liu, J.; Li, C.; Liu, Y.; Yu, F. Data Assimilation for Rainfall-Runoff Prediction Based on Coupled Atmospheric-Hydrologic Systems with Variable Complexity. Remote Sens. 2021, 13, 595. [CrossRef]

12. Zhu, Z.; Yang, Y.; Cai, Y.; Yang, Z. Urban Flood Analysis in Ungauged Drainage Basin Using Short-Term and High-Resolution Remotely Sensed Rainfall Records. Remote Sens. 2021, 13, 2204. [CrossRef]

13. Yasir, M.; Hu, T.; Abdul Hakeem, S. Impending Hydrological Regime of Lhasa River as Subjected to Hydraulic Interventions-A SWAT Model Manifestation. Remote Sens. 2021, 13, 1382. [CrossRef] 
14. Yang, S.; Li, C.; Lou, H.; Wang, P.; Wang, J.; Ren, X. Performance of an Unmanned Aerial Vehicle (UAV) in Calculating the Flood Peak Discharge of Ephemeral Rivers Combined with the Incipient Motion of Moving Stones in Arid Ungauged Regions. Remote Sens. 2020, 12, 1610. [CrossRef]

15. Qiao, S.; Ma, R.; Sun, Z.; Ge, M.; Bu, J.; Wang, J.; Wang, Z.; Nie, H. The Effect of Water Transfer during Non-growing Season on the Wetland Ecosystem via Surface and Groundwater Interactions in Arid Northwestern China. Remote Sens. 2020, 12, 2516. [CrossRef]

16. Zhang, Y.; Kong, D.; Gan, R.; Chiew, F.H.S.; McVicar, T.R.; Zhang, Q.; Yang, Y. Coupled estimation of $500 \mathrm{~m}$ and 8-day resolution global evapotranspiration and gross primary production in 2002-2017. Remote. Sens. Environ. 2019, 222, 165-182. [CrossRef]

17. Zhang, Y.; Chiew, F.H.S.; Liu, C.; Tang, Q.; Xia, J.; Tian, J.; Kong, D.; Li, C. Can Remotely Sensed Actual Evapotranspiration Facilitate Hydrological Prediction in Ungauged Regions Without Runoff Calibration? Water Resour. Res. 2020, 56. [CrossRef]

18. Luan, J.; Zhang, Y.; Tian, J.; Meresa, H.; Liu, D. Coal mining impacts on catchment runoff. J. Hydrol. 2020, 589. [CrossRef]

19. Zhang, Y.; Chiew, F.H.S.; Zhang, L.; Li, H. Use of Remotely Sensed Actual Evapotranspiration to Improve Rainfall-Runoff Modeling in Southeast Australia. J. Hydrometeorol. 2009, 10, 969-980. [CrossRef] 


\section{University Library}

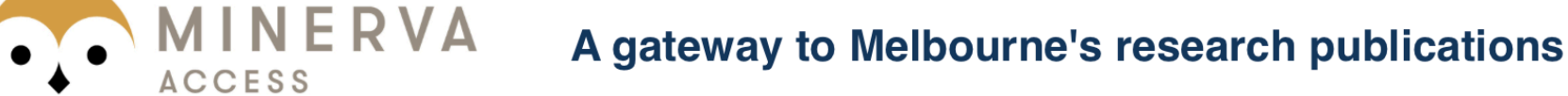

Minerva Access is the Institutional Repository of The University of Melbourne

Author/s:

Zhang, Y;Ryu, D;Zheng, D

Title:

Using Remote Sensing Techniques to Improve Hydrological Predictions in a Rapidly Changing World

Date:

2021-10-01

Citation:

Zhang, Y., Ryu, D. \& Zheng, D. (2021). Using Remote Sensing Techniques to Improve Hydrological Predictions in a Rapidly Changing World. REMOTE SENSING, 13 (19), https:// doi.org/10.3390/rs13193865.

Persistent Link:

http://hdl.handle.net/11343/286076

License:

CC BY 